\title{
Research and Application of Crystallization Technology in Treating Phosphorus Wastewater
}

\author{
Renzhen Cheng ${ }^{1, ~ a}$, Liping Qiu ${ }^{1, b^{*}}$, Liquan $\mathrm{Lu}^{1, \mathrm{c}}$, Mengfei Hu${ }^{1, \mathrm{~d}}$ and Zeyu Tao ${ }^{2, \mathrm{e}}$ \\ ${ }^{1}$ School of Civil Engineering and Architecture, University of Jinan, Jinan 250022, China \\ ${ }^{2}$ School of Municipal and Environmental Engineering, Shandong Jianzhu University, Jinan 250101, \\ China \\ a965510172@qq.com, blipingqiu@163.com, c24lu.liquan@163.com, d1576451173@qq.com, \\ ezeyutao@sina.cn \\ *Corresponding author:
}

\begin{abstract}
Keywords: phosphorus wastewater; crystallization; principle; influencing factors.
Abstract: At present, the crystallization method has become a hotspot in the field of wastewater treatment. The crystallization method not only remove phosphorus effectively in wastewater, but the phosphorus also can be recycled. The crystallization method includes ammonium magnesium phosphate crystallization method, calcium hydroxy calcium phosphate crystallization method, vivianite crystallization method and so on. The study introduced the principle of phosphorus removal and the influencing factors of the three crystallization methods, and discussed the effects of $\mathrm{pH}$, ion concentration and stirring conditions on the crystallization. $\mathrm{pH}$ has the greatest influence on crystallization among of them. The best $\mathrm{pH}$ of the vivianite crystallization is between 7 and 9 , and it is easier to form crystals in the general wastewater than MAP and HAP. In a certain concentration range, the phosphorus removal rate increased with the increase of ion concentration. In the case of air stirring or cyclical stirring, crystallization can be instantly formed, effectively increasing the crystallization rate. Finally, the application prospect of crystallization method in the treatment of phosphorus wastewater is prospected, which provides technical and theoretical support for the removal and recovery of phosphorus in wastewater.
\end{abstract}

\section{Introduction}

With the development of economy, people's living standards continue improving, the demand for phosphorus is also increasing. In nature, phosphorus is mainly present in the form of organophosphorus compounds and phosphates. On the one hand, Phosphorus resources are depleted because the existing reserves of phosphorus are only enough for 100 years for human; on the other hand, people use a lot of phosphorus-containing substances (fertilizer, laundry liquid, etc.), and eventually discharged into the water, resulting in water eutrophication and destruction ${ }^{[1]-[3]}$. Therefore, the removal and recycling of phosphorus should arouse our attention.

Sewage is rich in phosphorus which are mainly organic phosphorus, phosphate and its compounds. At present, the treatment of phosphorus in wastewater mainly bio-method, chemical method, crystallization method. At present, the treatments of phosphorus in wastewater are mainly biological methods, chemical methods, crystallization methods. Biological methods is more energy-efficient and low-cost, but phosphorus is difficult to recycle, and the treated sludge is likely to cause secondary pollution; Chemical method mainly includes iron salt and aluminum salt precipitation method, calcium phosphate precipitation method, chemical phosphorus removal can effectively remove phosphorus and more thorough, but the cost is higher and adding a large number of chemical agents is needed. The chemical sludge produced is enormous and the composition is more complex to recycle, which leads to fail to achieve the purpose of phosphorus resource recovery. Crystallization methods include ammonium magnesium phosphate (MAP) crystallization, calcium hydroxyphosphate (HAP) crystallization, vivianite crystallization method,can not only effectively remove phosphorus, but also recycle. This paper summarizes the principles and main influencing factors of three kinds of 
crystallization methods and its application and prospect in engineering. It aims to provide reference for improving the efficiency of phosphorus recovery and utilization.

\section{Principle of crystallization and phosphorus removal}

\section{MAP crystallization method}

MAP commonly known as struvite, can directly act as phosphate fertilizer, used in crops. MAP is white powder oblique rectangular crystal, molecular weight of 245.41 , slightly soluble in water, soluble in dilute acid, insoluble in alkaline solution. The magnesium ammonium phosphate produced reaction in waste water as follows:

$$
\begin{aligned}
& \mathrm{NH}^{4+}+\mathrm{H}_{2} \mathrm{PO}_{4}{ }^{-}+\mathrm{Mg}^{2+}+6 \mathrm{H}_{2} \mathrm{O}=\mathrm{MgNH}_{4} \mathrm{PO}_{4} \cdot 6 \mathrm{H}_{2} \mathrm{O}+2 \mathrm{H}^{+} . \\
& \mathrm{NH}_{4}{ }^{+}+\mathrm{HPO}_{4}{ }^{2-}+\mathrm{Mg}^{2+}+6 \mathrm{H}_{2} \mathrm{O}=\mathrm{MgNH}_{4} \mathrm{PO}_{4} \cdot 6 \mathrm{H}_{2} \mathrm{O}+\mathrm{H}^{+} . \\
& \mathrm{NH}^{4+}+\mathrm{PO}_{4}{ }^{3-}+\mathrm{Mg}^{2+}+6 \mathrm{H}_{2} \mathrm{O}=\mathrm{MgNH}_{4} \mathrm{PO}_{4} \cdot 6 \mathrm{H}_{2} \mathrm{O} .
\end{aligned}
$$

Magnesium phosphate crystallization reaction is divided into two processes. Firstly, the formation of nuclei (induction period); secondly, the stability of crystal (stable). Under certain conditions, the spontaneous formation of homogeneous nucleation finished and the nucleus will spontaneously grow to the solution balance when the solution reaches the supersaturation ${ }^{[4][5]}$. In the wastewater treatment, it is necessary to meet the higher phosphorus removal rate and improve the reaction rate. Generally joining the seed or change the external conditions is needed in order to form heterogeneous nucleation and induce crystallization.

MAP crystallization is a very complex reaction process. Control the crystallization conditions and it will improve the removal rate of phosphorus in sewage and get a better crystalline crystal products and more favorable sewage phosphorus and phosphorus recovery.

It was found that the main factors affecting the crystallization of MAP were: solution supersaturation, solution $\mathrm{pH}$, reaction time, molar ratio of crystallization ions, stirring speed, coexisting ions and substance concentration ${ }^{[6]}$.

\section{HAP crystallization method}

The principle of HAP crystallization method recycling phosphorus is that using the $\mathrm{PO}_{4}{ }^{3+}, \mathrm{Ca}^{2+}$ and $\mathrm{OH}^{-}$reaction in the sewage to produce calcium hydroxy phosphate. Through the phosphorus removal agent, so as to achieve the purpose of phosphorus recovery. The reaction is as follows:

$$
10 \mathrm{Ca}^{2+}+6 \mathrm{PO}_{4}{ }^{3+}+2 \mathrm{OH}^{-} \rightarrow \mathrm{Ca}_{10}\left(\mathrm{PO}_{4}\right)^{6}(\mathrm{OH})_{2} \downarrow
$$

As when the seed crystal containing calcium hydroxyphosphate is added to the unsaturated solution, the supersaturated solution calcium phosphate precipitation process of the induction period, the nucleation period and the amorphous phase of the precipitation phase will be eliminated, and thus come into the stable crystal crystal growth period directly.

\section{Vivianite crystal}

The chemical composition of vivianite is $\mathrm{Fe}_{3}\left(\mathrm{PO}_{4}\right)_{2}\left(\mathrm{H}_{2} \mathrm{O}\right)_{8}$, which is an aqueous iron phosphate minerals, white blue crystals, soluble in strong acid, and insoluble in water and ethanol. It is also the raw materials of $\mathrm{LiFePO}_{4}$. Laboratory commonly used $\mathrm{FeSO}_{4} \cdot 7 \mathrm{H}_{2} \mathrm{O}, \mathrm{Na}_{2} \mathrm{HPO}_{4} \cdot 12 \mathrm{H}_{2} \mathrm{O}$ and $\mathrm{CH}_{3} \mathrm{COONa} \cdot 3 \mathrm{H}_{2} \mathrm{O}$ as raw materials to prepare. If the vivianite is exposed to air, it is easy to oxidize. Morrie and Ito ${ }^{[7]}$ studied the crystal structure of the vivianite, and found that ferrous ions occupy two different octahedral crystal, one is isolated octahedron, the other is a common double octahedron.

In the sewage treatment system, the phenomenon of vivianite precipitation has always existed (especially in the use of iron salt to control ammonia Concentration) and is known to the people. This has been treated as a negative problem in the past, such as handling system clogging and sludge dewatering difficulties. The study on the removal and recycle of phosphorus from sewage or sludge in the use and strengthening of vivianite crystals has become a hot spot in recent years.Robertson et al. reduced the Fe (III) to Fe (II) by dissolving and reducing the solid phase iron ore using the method of 
filling the iron-rich soil filter column, and precipitated with $\mathrm{Fe}$ (III) and $\mathrm{Fe}$ (II) and $\mathrm{PO}_{4}{ }^{3-}$ To remove the phosphorus in the liquid phase system of septic tank.

In 2008, Cheng Xiang ${ }^{[8]}$ proposed sewage treatment system based on vivianite crystallization of sewage/sludge phosphorus recycle of new technologies: unit plus trivalent iron in the phosphorus-rich sludge anaerobic digestion through the sludge anaerobic release of phosphorus, sludge crack interpretation Phosphorus, trivalent iron anaerobic bio-reduction and vivianite crystallization process and will achieve efficient recycle of sewage phosphorus resources and improvement of efficiency of sewage treatment and reduce the production of sludge.

\section{Factors affecting the removal of phosphorus}

The study of crystallization conditions is to explore the conditions and parameters to accelerate the rate of nucleation and to promote crystal growth in order to improve the efficiency of phosphorus removal and recovery and reduce the reactor volume. The conditions and influencing factors of crystal formation are $\mathrm{pH}$, the molar concentration and ratio of the ions, the reaction time and so on ${ }^{[9]}$.

\section{Effect of pH on Crystallization}

$\mathrm{PH}$ has a great effect on the solubility of MAP and HAP, and the solubility of both decreases with the increase of $\mathrm{pH}$. The lowest solubility of MAP occurs at $\mathrm{pH}=10.3$, and after this value is exceeded, the solubility increases. In actual operation, the $\mathrm{pH}$ does not exceed this value. It is generally believed that the $\mathrm{pH}$ is more than 8.0 and the MAP crystals will be produced, but the efficiency depends on the amount of magnesium ions and $\mathrm{pH}$, the efficiency increases with increasing $\mathrm{pH}$; the best $\mathrm{PH}$ of vivianite crystallization is between 7 to $9^{[10]}$, it is easier to form than the crystallization of MAP.

\section{Effect of ion concentration on crystallization}

In the case of metastable sewage, such as sludge anaerobic digestion supernatant, sludge dewatering filtrate and aquaculture wastewater, the concentration of ammonia in water is high, which is a non-limiting factor of crystallization, while the concentration of magnesium ion is relatively low, and will limit the crystallization reaction. For the crystallization of MAP, the removal of $\mathrm{NH}_{4}{ }^{+}, \mathrm{Mg}^{2+}$ and $\mathrm{PO}_{3}{ }^{4-}$ is 1: 1: 1 in stoichiometric relationship. However, $\mathrm{NH}_{4}{ }^{+}$and $\mathrm{Mg}^{2+}$ need to be surplus in order to achieve higher phosphorus removal efficiency. Therefore, the molar ratio of $\mathrm{Mg}$ to $\mathrm{P}$ has a decisive effect on the efficiency of phosphorus removal. The results showed that when the ammonia concentration increased from $100 \mathrm{mg} / \mathrm{L}$ to $500 \mathrm{mg} / \mathrm{L}$, the removal rate of $\mathrm{P}$ increased with the increase of ammonia concentration, and the purity of MAP increased with the increase of ammonia concentration.

\section{Effect of agitation on crystallization}

It was found in the experiment that the stirring condition had a significant effect on the effect of Fe reduction on phosphorus precipitation, while other conditions such as temperature, substrate concentration and reaction time period had no significant effect on the phosphorus removal effect ${ }^{[11]}$. Ammonium phosphate and calcium hydroxyphosphate crystals and stirring effect is also very prominent. The crystallization rate and the stirring speed is positively correlated in a certain range, but the stirring speed exceeds a certain limit after the crystallization effect change is not obvious ${ }^{[12]}$.

\section{Application and Prospect of Crystallization and Phosphorus Removal in Engineering}

The crystallization reactors that have been developed mainly have some of the following categories: DHV CrystalatorTM system, Kurita fixed bed crystallization reactor, phosnix process and so on. They have been into the practical application in Japan. A domestic company have built a set of ammonium magnesium phosphate crystal removal process equipment in 2009 in order to deal with high concentrations of phosphorus-containing wastewater produced by chemical production process.

Crystallization products can be used as slow-release fertilizers, $\mathrm{P}$ industrial raw materials for the manufacture, the materials for fire-resistant plates and also used for cement production as supplement for the lack of natural phosphate rock ${ }^{[13]}$. Calcium phosphate crystallization method is widely used to remove phosphorus removal in landscape water ${ }^{[14]}$.In the wastewater treatment, the crystallization 
method with its unique advantages of phosphorus resource recovery has been widely concerned. HAP, MAP crystallization recovery of phosphorus research gradually put forward. vivianite, as a The potential of the crystallization of the way, will become the future of water treatment workers one of the essential content.

\section{Acknowledgements}

This work was financially supported by National Natural Science Foundation of China (51678276), Science and technology development projects of Shandong province (2016GSF117012, 2016CYJS07A03-3).

\section{References}

[1] Yuxin Zhang, Jun Yin, Helong Yu, et al. Study on Influencing Factors of Ozone Oxidation. Journal of Jilin Agricultural University[D], 2010, 32(5), 523-527.

[2] Weihua Song, Jun Yin, Junhua Cao, et al. Recovery of High-Concentration $\mathrm{NH}_{3}-\mathrm{N}$ in Landfill Leachate by MAP Chemical Precipitation. Journal of Jilin Agricultural University[D], 2012, 34 (3), 316-320.

[3] Hongjie Song, Shaohua Yang, Yubo Cui, et al. Research and Application of Constructed Wetland in Rural Sewage Treatment. Journal of Jilin Agricultural University[D], 2013, 35(3), 328-333.

[4] Mehta C M, Batstone D J. Nucleation and growth kinetics of struvite crystallization. Water Research[J], 2013, 47(8):2890-2900.

[5] Ariyanto, Eko, T. K. Sen, and H. M. Ang. The Influence of Various Physic-Chemical Process Parameters on Kinetics and Grow Mechanism of Struvite Crystallization. Advanced Powder Technology[J], 2014, 25(2), 682-694.

[6] Corre, Kristell S. Le, et al. Impact of Calcium on Struvite Crystal Size, Shape and Purity. Journal of Crystal Growth[J], 2005, 283, 514-522.

[7] Yingjun Du, Xinjun Shen, Yanping Li. Study on Influencing Factors of Nitrogen and Phosphorus Recovery from Wastewater Treatment by Ammonium Phosphate. Water treatment technology[J], 2012(s1):19-22.

[8] Xiang Cheng. Phosphorus recovery from sewage water by layered double hydroxides as an adsorbent and by vivianite precipitation. Harbin Institute of Technology[D], 2010.

[9] Chunyang Zhang, Jianguang Liu, Aihua Wang, et al. Development and Application of Phosphorus Removal by Crystallization Technology. Energy-saving technology[J], 2006, 24(135), 63-69.

[10] Ronghua Yu, Lili Ding, Hongqiang Ren, et al. Research Status of Struvite Chemical Crystallization Technology. Industrial water and wastewater[J], 2014(6), 1-3.

[11] Jue Wang. Continuous-Flow Study of Enhanced Phosphorus Removal from Sewage Via Vivianite Crystallization. Beijing Forestry University[D], 2016.

[12] Jun Chen. Study on Recovery of Phosphorus from Excess Sludge by Crystallization of Vivianite Based on Fe (III) Reduction. Beijing Forestry University[D], 2015.

[13] Janhua Wang. Application of Magnesium Ammonium Phosphate Crystallization for Phosphate Removal in Waste Water Treatment. Energy and Chemical Industry[J], 2013, 34(5), 41-44.

[14] Linjie Wang. Study on the HAP Crystallization Process for Phosphorus Rremoval of Csenic Water with Source of Reclaimed Water. Capital Normal University[D], 2013. 